\title{
Analysis on the Charm of Football from the Perspective of Dialectics
}

\author{
Feng Xiao \\ Guangdong University of Foreign Studies, Guangzhou, China \\ Email: xiaofeng@gdufs.edu.cn
}

How to cite this paper: Xiao, F. (2020). Analysis on the Charm of Football from the Perspective of Dialectics. Advances in Applied Sociology, 10, 498-503.

https://doi.org/10.4236/aasoci.2020.101202

$\underline{9}$

Received: November 23, 2020

Accepted: December 14, 2020

Published: December 17, 2020

Copyright $\odot 2020$ by author(s) and Scientific Research Publishing Inc. This work is licensed under the Creative Commons Attribution International License (CC BY 4.0).

http://creativecommons.org/licenses/by/4.0/

\begin{abstract}
Dialectics offers us an excellent perspective on understanding the laws and nature of things. It is manifested in football, the most popular sport in the world, in many aspects, including the result of competition, switch between offense and defense, team and its player, "justice" and "injustice", and joys and pains brought to the audience. Analyzing factors that make football so popular based on dialectical thinking is not only a flexible application of dialectics, but also instructive for us to understand the nature of football and better promote it.
\end{abstract}

\section{Keywords}

Dialectics, Football, Charm, Dialectical Relationship

\section{Introduction}

Since its birth in 1863 , football has fascinated millions of people and quickly developed into the most popular sport in the world. Every session of FIFA World Cup is a wonderful feast for football fans worldwide, bringing them great delights and much to linger on. It is estimated that there are now billions of football fans around the world. Football is charming and even magic for many reasons, a major one of which is believed by the author is the rich dialectic thoughts contained in it. A football match is sometimes is the condensation of social phenomena. A high-level football match may fully reveal dialectical relations in human world, which is quite impressive. In this study, the author attempts to analyze the charm of football from five typical aspects with dialectical thinking and further understand the nature of football. 


\section{Dialectics in Football from Five Perspectives}

\subsection{Win and Lose Reflect the Dialectical Relationship between Inevitability and Contingency}

Generally speaking, teams in a certain level of competition are relatively strong ones among all teams at the same level. As a result, every football team that competes at its level has a good chance of winning. However, the result of a competition reflects the dialectical relationship between inevitability and contingency.

Inevitability refers to a stable development trend that arises from the main aspect of the inherent contradiction of things under certain conditions that determines its development direction, while contingency refers to an unstable development trend that arises from the secondary aspect of the inherent contradiction of things under certain conditions which determines its development direction (Hou, 2008). In the course of the development of things, inevitability is a decisive factor, but it is shown through contingency. Countless contingencies constitute inevitability. In a certain stage or part of the development of things, contingency also plays an important role, and sometimes even dominates the outcome of things at a certain stage or part of development.

The final result of a football match is determined by the strength of players. Strength is a decisive factor in determining the outcome of a game, also an inevitable factor. However, every football match is full of numerous contingencies, any one of which can affect the outcome of the match. If the outcome of a football match is determined only by the strength of players, football would have no charm. One of the great attractions of football is that there are so many chances. In the 2018 FIFA World Cup held in Russia, Argentinian football star Lionel Messi lost a penalty that should have gone in against Iceland by Icelandic goalie Halldorsson, which was a great pity for Messi's fans worldwide (Ma, Ren, \& Yan, 2018). A lot of "shouldn't have" goals have been scored, which was baffling. Sometimes a strong team plays offensively, but does not score a goal. Sometimes the weak team has a hard time defending, but "accidentally" scores when getting a chance. More occasionally, "own goal" makes players and their fans regret deeply or even for a lifetime.

Although there are possibilities of "contingent events" or even "accidents" at any time, strength is still a decisive factor. A "weak" team may "accidentally" win one or a few games, but it can't win every game. It is impossible for world recognized "weak" teams to win the World Cup. The appeal of the World Cup is that it is played by the world's top teams, many of whom are so closely matched that any chance on the pitch can affect the outcome. The suspense at the beginning of the game is essentially the "contingencies" that may happen. The game is memorable because of dramatic "contingencies". This is a major reason why football is so attractive.

\subsection{Attack and Defense Embody a Contradictory Dialectic Relation}

The subtlety of unity of opposites is that it understands everything and problems 
as contradictions formed by opposing parties. Contradictions are everywhere and exist all the time (Zhang, 2018), which is also true to football. In football match, attack and defend is a pair of contradictions. If a team wants to dominate a game and win, it must attack. In order to avoid being in a disadvantaged position or failure, it must defend. Strength in offense and defense are two basic aspects to measure the strength of a team, which constitute a pair of typical "contradictions". Any team hopes that their offensive "spear" can break through all the defensive "shield", and hope that their defensive "shield" can stop all the offensive "spear". That's a contradiction.

Generally speaking, in a football match, every team hopes to win. If a team wants to win, it must attack. In the early days, the "99" system dominated by attacks was adopted. However, too much emphasis on attack will lead to loopholes in defense. When a loophole in defense appears, the opponent team may score a goal. Later, emphasis was put on defense, but pure defense without offense is quite ineffective. Therefore, many coaches believe that offense is the best defense. Although modern football puts equal emphasis on attack and defense, fast attack and defense, fast switch between offense and defense, they are difficult to achieve. Generally speaking, the team that makes them will win the game. The ability to achieve these is the embodiment of strength. The whole game is featured by "you attack me, I attack you". A team will attack and defend from time to time. It is in the process of switch between attack and defense that teams are sharper than "spear" in attack and more solid than "shield" in defense. Every team wants to play against each other and take the initiative, but is often powerless and counterproductive. Therefore, it is the fast transition between attack and defense in football match that makes it enjoyable and interesting.

\subsection{Players and Teams Reflect the Dialectical Relationship between the Individual and the Collective}

A team is composed of several players. The relationship between each player and its team on the pitch reflects the relationship between the individual and the collective in real society. People are social people that live in a particular group. Carl Marx once pointed out that in reality, man is the sum of all social relations (Zhang, 2015). The society is a way of individual existence. "Wolf children" who live isolated from the society have no human significance. Thus, the individual cannot leave the collective. However, in real life, people sometimes feel the relationship between the individual and the collective is not obvious or strong, but football games fully show it in a condensed way.

Football matches, whether five-a-side or ten-a-side, are all team events that require smooth and tacit cooperation of players to give full play to the power of the collective. Besides, the technical and tactical level of each player and the level of play in the game will have an important impact on the outcome of the game. Usually, a team that attracts more fans has one or more stars. The super strong ability of individual stars and their demonstration and driving effect in the team often bring the whole team great encouragement and confidence. Therefore, 
there is a benign interactive relationship between the team and the stars: a first-class team tends to cultivate first-class stars, while first-class stars come from first-class teams and promote the strength of such teams. The tacit cooperation between ordinary players and stars is the premise and foundation for a team to play at a high level, even beyond the normal level. Countless facts have shown that if players in a team do not properly handle the relationship between the individual and the collective, the team cannot achieve good results. The tacit understanding between individual stars' skill and the team as a whole is often the concentrated embodiment of a high-level match.

\subsection{Justice and Injustice Shows Mankind's Unremitting Pursuit of Fairness and Justice}

Fairness and justice is an eternal pursuit of mankind, but unfair and unjust things often occur in human society.

Football match, a public game for human beings regardless of class, nationality, race, gender or region, is supposed to be a fair and just experience. However, in reality, many matches are contests and displays of justice and injustice. In order to prevent unfairness, people made many rules. However, there is almost no game without "foul" phenomenon. In addition to "unintentional foul", there are "intentional foul" and "tactical foul". A "foul" is an offence against the rules, an offence against fairness and justice. The reason why every foul should be punished accordingly is to compensate for fairness and justice. The problem is that many fouls in football match go unpunished, which make fans quite angry. The referee is supposed to be a symbol of fairness, but it is never easy to ensure entire fairness. Even though the referee tries his best to enforce rules impartially, it is hard for him to be completely fair objectively due to the fast break and fast pace of modern football. Therefore, "misjudgment" is inevitable. The 2018 World Cup in Russia used a video assistant referees system for the first time to assist referees, aiming to reduce "misjudgment". Former FIFA President Sepp Blatter once said that "misjudgment is part of the charm of football" (Liang \& Yang, 2011), which sparked an international uproar among fans. When a referee takes sides, unfair decisions are enough to make fans get annoyed. What is more intolerable is that once the game is controlled by some interest groups, "black whistle" will "desecrate" the noble sport and make the game lose its value. Mr. Blatter might have put it more aptly: that people always seek justice in football, but it is hard to eradicate injustice. That is perhaps the appeal of football.

\subsection{Joy and Pain Reflect the Dialectics in the Change of Human Emotions}

The road ahead is never plain sailing, and the development of things is never smooth. As an ancient Chinese saying goes, "Misfortune might be a blessing in disguises, and vice versa", which illustrates the dialectic of the transformation between misfortune and blessing. With the switch of fortune and misfortune, people's emotions also change. When things go well, people are often intoxicated 
with joy. When people are frustrated, they are often in great pain. Life seems to be played out in alternations of pleasure and pain. Football match is a process in which fans experience joy and pain alternately. A good football enables fans to feel rapid switch of joys and pains in a short period of time. This is often where many fans find a game "enjoyable".

A World Cup is a feast or even a carnival for fans worldwide. When the team supported by fans play well, the fans would hail in great joy; when it suffers a setback, the fans would be miserable, wringing their hands and sighing. The whole game seems to pass unconsciously in transition of smoothness and frustration, blessing and misfortune, joy and pain. This rapid shift between pleasure and pain has a great attraction for many young people and powerful impacts on their emotional world. It also poses a potential threat to football fans suffering from heart disease and high blood pressure. It's no wonder that there are fans dying accidentally during every World Cup (Yang, Zheng, \& Cong, 2014). In addition, every game starts with the anticipation of all the fans for the team they support, so the entire stadium is a sea of joy before the game begins. But at the end of the game, the fans of the winning side are happy, while the fans of the losing side are depressed. Both winning and losing fans always have something to be happy about and something to be sorry about.

\section{Conclusion}

The rich dialectic thoughts contained in football, the most popular sport in the world, is one of the key reasons for its great charm. In this study, dialectics in football is analyzed from five typical aspects, which run throughout a football game and can be revealed in each game. Of course, in addition to these five perspectives, there are many similar dialectical relations in football matches, such as purpose and result; subjective and objective; fast and slow; rules and creativity; strategy and tactics; internal and external causes; quantity and quality. It is the constant interpretation and full expression of these relationships that make football so charming. In this study, the author analyzed the charm of football from five typical aspects with dialectical thinking, which is not only a flexible application of dialectics, but also instructive for us to understand the nature of football and thereby better promote it.

\section{Conflicts of Interest}

The author declares no conflicts of interest regarding the publication of this paper.

\section{References}

Hou, G. Y. (2008). A New Study of Inevitability and Contingency. Journal of Henan Normal University (Philosophy and Social Sciences Edition), 1, 9-13.

Ma, J., Ren, R., \& Yan, J.N. (2018). Why the Superstar-led Team Was Defeated. Tsinghua Business Review, 12, 20-26.

Zhang, K. L. (2018). On the Practical Gene of Dialectics. Marxist Philosophy. 
Zhang, K. L. (2015). Human Nature: Marx's Response to the Highest Issue of Philosophy. Journal of Peking University (Philosophy and Social Sciences), 5, 5-17.

Liang, H. B., \& Yang, X. S. (2011). Evolution of Rules for Modern Football Competitions and the Necessity and Idea of Amending Them as Soon as Possible. Journal of Physical Education, 2011, 110-114.

Yang, S., Zheng, F., \& Ping, C. H. (2014). Research on Professional Football Industrial Policy in European Countries-Taking Experience in United Kingdom, Germany, Spain and Italy as Example. China Sport Science, 5, 75-88. 